\title{
International Training Course on the Use of Radioisotopes and Radiation in Forestry Research
}

\section{A. Fraser, RPF ${ }^{1}$ and E. E. Gaertner, $P_{A g}^{2}$}

The period May-July, 1965, marked another first in forestry science when the first international course on the application of radioisotopes and radiation in forestry research was inaugurated at the Technical University of Hanover, West Germany. This course was sponsored by the Food and Agriculture Organization of the United Nations and the International Atomic Energy Agency through their Joint Division of Atomic Energy in Agriculture, and was intended to bring this modern tool of science within reach and comprehension of qualified workers in the field of forestry research. It was to follow a norm previously developed for the application of radioisotope techniques in agriculture, animal husbandry, etc.

The German Federal Government, the local Government of Lower Saxony and the Technical University of Hanover were the hosts. The course was held at the newly built Institute of Radiobiology that forms part of the Faculty of Horticulture of the Technical University of Hanover. Dr. Glubrecht, the Head of the Institute for Radiobiology, became the Director of the course. The senior author was appointed as Associate Director to balance the team with experience in forestry. The first half of the course was concerned primarily with the theoretical aspect of the subject, the fundamentals of nuclear physics, various types of radiation and essential calculations, and was handled by the Institute staff. The second half attempted to cover all phases of forestry and its industry and to suggest the possible aid offered by the radioisotope techniques. It shall be credited to the prestige of the sponsoring bodies that the various phases of this broad field were covered by specialists of world renown, who arrived durng the course to deliver individual lectures and conduct specific laboratory experiments. Thus wood technology was handled by Dr. Schweers (Germany), entomology by Doctors Eidman (Sweden) and Keller (IAEA), pathology by Dr. Sauvelescu (Romania), genetics by Dr. Gustafsson (Sweden), soils by Dr. Yassaglou (Greece), etc. The senior author's role of Associate Director meant that besides helping to chart the whole course, consulting on the selection of visiting specialists and presenting his own subject of tree physiology, he was responsible for the integration of these lectures and for ensuring that the laboratory experiments could be carried out as planned. It was also left to him to fill any gaps in the fields which were not covered by these specialists, who at times concentrated on very specific problems, and to be ready for any last minute substitution, i.e. impromptu lectures.

In addition to the 100 hours of lectures, 30 experiments and eight demonstrations, the course members were taken on several excursions to forests, research stations, and universities of special interest.

\footnotetext{
${ }^{1}$ Research Officer, Dept. of Forestry of Canada, Petawawa Forest Expt. Station, Chalk River, Ontario.

"Economic botanist, Dept. of Forestry of Canada, Petawawa Forest Expt. Station, Chalk River, Ontario.
} 
One trip was to the Nuclear Research Centre at Karlsruhe, with a planned detour through the Black Forest. Unfortunately the continuous rain and low cloud over the Black Forest prevented peripatetic inspection and the Black Forest was henceforth referred to as the "White Forest" by some of the students. On the excursion to the Faculty of Forestry and surrounding area of Hannoversch-Münden we had an interesting incident. The Oberforstmeister in response to a question said that forest fires were never a problem in their climate, and a few minutes later the bus rounded a corner on a bush road only to be stopped by the local fire brigade with pumpers and hoses (extended from a nearby stream) dousing a fire burning in a quarter-acre of Scots pine slash.

The facilities of the "swimming pool" type of reactor (similar to the one at McMaster University) were demonstrated on the tour of the Nuclear Station, Geesthacht, near Hamburg. Although the purpose of the nuclear station was the development of a marine nuclear propulsion engine, its facilities were available to the Institute for Radiobiology at Hanover. It was at this reactor that pollen obtained from a Scots pine tree injected with manganese was activated. This particular experiment conducted for the students may be of especial interest to Ontario foresters. In following pollen distribution from a specific tree, one immediately thinks of tagging the pollen grains with radioisotope injected into the trunk and translocated to the pollen grains just before dehiscence of the pollen sacs in the spring. However, in populated regions this may not be feasible because of possible contamination of the local inhabitants or their food. An alternative is to label the pollen grains by injecting a non-radioactive compound (such as manganese sulphate) into the trunk about four weeks before pollen dispersal. Then, drying this dispersal, the pollen grains are collected on sampling polyethylene strips at various distances from the injected tree. These "collectors" receive, of course, pollen from both injected and non-injected trees. When they are exposed to a thermal neutron flux in a suitable reactor for a period of 20 minutes, the pollen grains with the manganese deposited in them will then become radioactive. A photomicrograph of the "collector" with the activated (radioactive) manganese-containing pollen grains will record these grains. By microscopic examination of the exposed film with the record of the activated pollen grains (dark dots) and the actual collector strips, the proportion of pollen from the labelled trees can be calculated. One can visualize other applications of this technique in industrial operations where it is not feasible to introduce a radioisotope into the operation, and yet use the sensitivity of tracer methodology.

We can see the day coming when tree breeders will be on nearly equal footing with the zoologists who work with the fast developing (10 day life cycle) Drosophila (fruit fly). On our inspeciton of the Forest Research Institute near Hamburg we saw this coming revolution in the development of the special birch strain which can take less than two years from the time of germination to seed production. It was amazing to see the few-inch-high tree "seedlings" producing flowers and seed, and this material should prove useful both to the geneticists and physiologists who are studying flower and seed production. 
We have already mentioned that all aspects of forestry were examined, ranging from fundamentals such as physiology and pathology to the applied field of wood preservation. The students were even more varied both in their national origin and interest. One prerequisite for attendance was a knowledge of English, for that was the official language of the course. The 23 students represented 23 countries from five continents, and specializations in most branches of forestry, so that at least one member in the audience was vitally interested in each lecture presented. If some political implications were considered, the course was a model in coexistence. First came the problem of obtaining visas for some of the nationals not usually welcomed in West Germany. Although this extended beyond the official opening of the course, it was solved to satisfaction, and the German members of the staff attached great value to this universal acceptance. Next came the actual attitude of individuals representing different national interests. Here the value of professional interests in the smoothing of ideological controversies should be stressed, for they dominated the course to the complete exclusion of the latter. Individuals were accepted on the basis of personal qualifications. Most tried to be ambassadors of their countries and make their attributes known to the rest. Some interesting facts emerged: Films from Argentina reminded us strongly of our own midwest and the Calgary Stampede. The plight of one Asiatic nation was realized when it came under discussion that its script was "modernized" about 20 years ago and has now reverted to the original. Just imagine having to learn to write your own language twice in a lifetime. The participant from a country in Asia Minor had never seen a pig or known rhubarb before. One participant from the southern hemisphere expressed amazement that not all German girls were blonde and blue-eyed as he expected. A general astonishment was voiced when we showed pictures from our Petawawa gardens, for many did not associate the decorative oriental poppy with our climate.

The massive production of Volkswagens was an obvious and striking example of the new West German affluence. A steady stream of long, doubledecker freight trains, loaded to capacity with Volkswagens, passed continuously by our apartment window during late afternoons and evenings. The renewed German influence both in the international scientific field and on the world market was easily apparent. We have met several scientists with research projects in underdeveloped countries and the labels both on foods and manufactured goods showed a great diversity. It should be noted here that this wide variety of foodstuff was not confined to the Common Market, which of course was most obvious, especially in such commodities as tomatoes and cucumbers, but included the eastern European countries, Africa, etc. We found for instance, frozen chickens imported from five different countries (Canada was not represented).

It was revealing to realize the acute manpower shortage both on skilled and unskilled levels. There are several new universities being established in Germany and staffing these, as well as the replacement of retiring professors, is becoming of deep concern. In the field of forestry alone, there are now two professorial chairs open, both at well known and established faculties. When one realizes that each Institute has only one full professor, the 
magnitude of need becomes more apparent. On the other end of the scale is Germany's ever-growing need for more workers for their busy factories. These come primarily from the underdeveloped southern countries and are referred to as "guest workers". Only the men are usually in evidence and the title defines their temporary status. It is interesting to note that a new type of discrimination is appearing and we have seen several big billboards proclaiming "The guest worker is thy neighbour too".

This economic resurgence has also changed the German's attitude towards emigration. Although young girls are willing to take jobs as domestics or nurses (only jobs that are usually open to them) in England or North America, most are interested in learning the language rather than making a permanent commitment. And while many ambitious Germans skilled (including professionals) and unskilled could see only a limited future in their own country a few years ago and have dispersed widely over the world, we have met several that have now returned to resume their life in Germany.

Students from the following countries participated in the course. If any Canadian forester has occasion to visit these countries, the authors will be glad to provide the names and interests of course participants on request.

Argentina, Australia, Austria, Brazil, Bulgaria, Canada, Czechoslovakia, Finland, West Germany, Hungary, Israel, Italy, Japan, New Zealand, Pakistan, Philippines, Poland, South Vietnam, Sweden, Syria, Thailand, United States of America.

\section{IUFRO MEETING}

In agreement with the President of IUFRO, Professor Dr. Dr.h.c. J. Speer, the German Union of Forestry Research Organizations (President, Professor K. Mantel) takes pleasure in giving notice that the next IUFRO Congress will be held in Munich from 4-9 September, 1967.

There will be prepared major excursions covering the entire territory of the Federal Republic in addition to various excursions being arranged for certain geographic areas and special fields of forestry.

The IUFRO Congress Bureau has been set up in Munich 13, Amalienstrasse 52/11, West Germany.

\section{Background to Adoption of ONTARIo Log Rule}

Lettens from Professor F. M. Buckingham, Faculty of Forestry, University of Toronto, and Mr. C. R. Mills, formerly Secretary-Manager, Ontario Forest Industries Association and Member, Joint Industry Scaling Committee, take exception to the following statement in my article "The Measurement of Forest Products in Canada: Past, Present and Future. Historical and Legislative Background", published in the March issue of the Forestry Chronicle:

"Despite industry opposition to the proposed change, the Ontario Log Rule was developed by the Minister, February 15, 1952."

The words "despite industry opposition" are deemed to be too strong and my correspondents suggest that they "convey to the uninformed the convicition that the forest industry in Ontario was unalterably opposed to the introduction of the Ontario Log Rule. Such I am assured "was definiely not the case".

This matter would have been placed in better perspective had I quoted the 